\title{
Thinking about a joint-use library?
}

\section{A Memorandum of Agreement and timetable can ensure success}

\author{
by Kathleen Schwanz
}

$\mathbf{P}$ roviding quality library service points at reasonable cost continues to make jointuse libraries an attractive option. To thrive in today's marketplace, many types of academic institutions, including multicampus and single-campus universities, community colleges and schools, have opted to join forces with each other and even with hospitals, governmental installations, and corporations to provide better or more convenient facilities for their customers. The spirit of the resulting joint-use libraries, of course, is unique and influenced by many variables, including the participating institutions involved and the community served.

Whether the result of extensive planning, surveys, and assessments of specific service areas or of something innocuous like an informal brainstorming session by individuals from different institutions, a cooperative venture can be brought into being. Improved service and actual evidence of value to each participating institution should be the soughtafter goals. The impetus for the arrangement should motivate and serve as the guiding force in building a strong alliance among the participants.

A mutual objective, complementary needs, shared risks, and trust building are all key elements of a successful partnership. ${ }^{1}$ If the stimuli for cooperation are one-sided or if benefits accrue to individuals rather than or- ganizations, a cooperative venture should not be pursued. ${ }^{2}$

Planning for a cooperative undertaking should begin with an overarching vision but the operational process must be factored into the plan, as well. To accomplish the big picture goals, those expected to implement the plan should be participants in the planning process. ${ }^{3}$ Because so many factors affect the outcome of an alliance, inclusivity in the process rather than exclusivity should be sought. Oft times, it is the little things that sink or sabotage a relationship. They are important enough that they should not be an afterthought.

Ensuring the success of any joint-library venture requires careful planning by all the institutions involved and thoughtful implementation. In administering all aspects of the venture, no one institution should be in a situation of assuming something should happen or that something should be one particular institution's role; a good rule of thumb, especially for a joint-use library, is clarity in all things.

Two written documents are recommended to provide requisite structure for a project. The first is a written Memorandum of Agreement (MOA) to remind participants of their joint-venture agreement. The second document is a timetable of the planning and implementation phases to move the project along

\section{About the author}

Kathleen Schwanz is Spokane campus librarian at Washington State University and managing librarian for Cooperative Academic Library Services (a joint-use library of WSU Spokane and Eastern Washington University), e-mail: schwanz@wsu.edu 
in an agreed-upon fashion without any of the participants feeling pressured or hurried.

The details surrounding joint-use libraries are as unique as the libraries themselves. To aid individuals considering a joint-use library venture, points to cover in a MOA (MOA rhymes with boa) will be detailed in the remaining paragraphs. Timetables of the planning and implementation phases will be left to the readers' discretion. At the end of the article, some selected implementation and evaluation issues will be explored.

\section{Creating an MOA}

All parties should come together to create an MOA. It should begin with a general agreement regarding the scale of the joint-use library and the services to be provided.

Budget. The MOA should delineate how the venture's annual budget is to be constructed. Should each institution be billed to make a common joint-library budget, should all line-items remain with the originating institutions, or should some combination of the two be used?

Typically, a good document would include the following costs — each item broken down by percentage being shared by each institutional party:

1. identification of ongoing costs such as staff, goods and services, initial acquisition of materials, equipment and travel;

2. start-up costs for computing equipment and related telecommunications;

3. start-up costs for furniture, shelving, area dividers, and any additional equipment; and,

4. space costs by projection of needed space for library collections, growth, and ample study space.

Iepending on the type of institution involved, percentages of costs could be based on enrollment, clients served, or services rendered. During this phase of planning, a discussion of grant sources or fundraising alternatives to purchase needed items could be conducted.

Management and organization. Additionally, the MOA should delineate the jointuse library's management and organizational structure. Should institutions that contribute more heavily dictate what the joint-use library's management should be or should each party be an equal partner?

\section{Ensuring the success of any joint- library venture requires careful planning by all the institutions involved and thoughtful imple- mentation.}

Although a joint-use library's management and organizational structure may seem very straightforward, differing organizational missions and climate in the parent institutions may lead to differing expectations at the planning table. Avoid surprises by exploring institutional differences ahead of time; exercise clarity by careful planning.

Policies and procedures. During the planning of the MOA, major policies and procedures for the joint-use library should be decided, including those for circulation, $\mathrm{col}^{-}$ lection development, acquisition, cataloging and processing, interlibrary loan, document delivery, and reference services. Although it would seem this planning would take the flavor of "how something is accomplished" or a "who does what" among institutions, the clientele served and service quality should not be neglected. Who are the joint-library's potential users and how shall they be treated? Are there other potential unaffiliated groups and what provisions need to be made for them? Fee-based and other services to the greater community need to be considered.

Location. The last factor, the location of the joint-use facility, is a major consideration that can be comparatively easy to decide . very few places in the community offer enough square footage at a good price) or a major stumbling block (the inner city versus the suburbs). Because it could determine whether the project moves forward, the discussion about where to locate shouldn't be left until the end.

\section{Implementation: putting the agreement to work}

As noted above, a written timetable of the planning and implementation phases enables all participants to realize their joint expectations. Such documents inspire trust. Robert Frost's famous words, "Good fences make good neighbors," are never truer than 
on the subject of joint-venture libraries. When participants do not follow through with their agreed-upon points on time, problems arise.

Partnerships are far less untidy in the abstract than in real life. What makes this so is the addition of people and their ways of behaving and doing things. They create the environment in which the partnership will thrive or not-whether congenial or hostile. Those who work the front lines of a joint venture need to feel secure in their own positions; they must trust one another; and, in the best of circumstances, they should believe in the legitimacy of the union.

Although difficult to generalize in ventures as unique as joint-use libraries, conflicts borne of institutional differences are bound to arise, whether the library opens with brand new employees or chooses seasoned veterans from each institution. For individuals planning joint libraries, the stress of bringing an inexperienced, opening-clay staff up to speed must be weighed against putting together a seasoned staff of wouldbe adversaries from each institution ready to call home with any perceived problem or infraction. For these reasons, a mixture of very new employees and veterans works best. Whatever the method used, strategies to handle the common conflicts that arise should be resolved ahead of time.

Even in the best implementations, differences in mission and organizational culture can sometimes threaten the fleclgling library and affect service quality. Examples include differing institutional attitudes concerning procedures (insisting upon a rigid workflow vs, encouraging employee latitude), how business is conducted (conducting face-toface service transactions vs. doing business through e-mail and the Web), and training opportunities available (taking care of business vs, promoting employee lifelong learning). Again, frank discussions of dormant problems by all the parties involved are absolutely necessary. Such discussions form the basis of the mission and organizational culture of the evolving joint-use library.

\section{Partnership: fait accompli}

Organizations need to ask themselves what outcomes they hope to achieve by combining operations. These questions must be answered candidly with acceptance of good and bad scenarios playing out. Based on what develops from questions, answers, and what the planning group decides it can live with, a cooperative facility is born or not.

If the decision is made to proceed with a joint-use facility, all that hard work that was realized will continue to be used because the MOA is a living document. It will change as the new library evolves and it becomes clear that many pre-partnership assumptions do not pan out while several unanticipated ones do. Once the joint-use library is in service, the evaluation process will begin and how well this new partnership was implemented and operates will be assessed. Results of the evaluation will (or should) cause the partners to begin tweaking problem areas. Problem areas can be things such as services, processes, and personnel. Essentially, the evaluation and fine-tuning cycle should occur throughout the life of the partnership to ensure success of the venture.

\section{Notes}

1. Harvey Meyer, "My Enemy, My Friend," Journal of Business Strategy, 19 (1998): 42-46.

2. Richard M. Cyert and Paul S. Goodman, "Creating Effective University-Inclustry Alliances: An Organizational Learning Perspective," Organizational Dynamics 25 (1997): 45-57.

3. Maxine Marks Teitler, "Alliances Are Not Mergers: What Problems Should You Expect?" Nonprofit World, 17 (1999) - 51-53.

\section{Register for ACRL preconferences}

Save your spot in one of these ACRL preconferences, which will be held prior to the ALA Annual Conference in Chicago on Friday July 7 :

- Legislative Advocacy: Key Roles for Today's Academic Librarians;

- Shining a Flashlight on the Library, Technology and the Curriculum: Designing Your Own Study;

- Understanding the Licensing Landscape; and

- Beyond Words: Visual Information in Special Collections (July 5-7);

Visit http://www ala.org/acrl/confhp. html for registration details. 


\section{LASTING RELATIONSHIPS ARE BUILT ON TRUST.}

\section{HAVING AN EXCEPTIONAL PRODUCT LINE DOESN'T HURT, EITHER.}

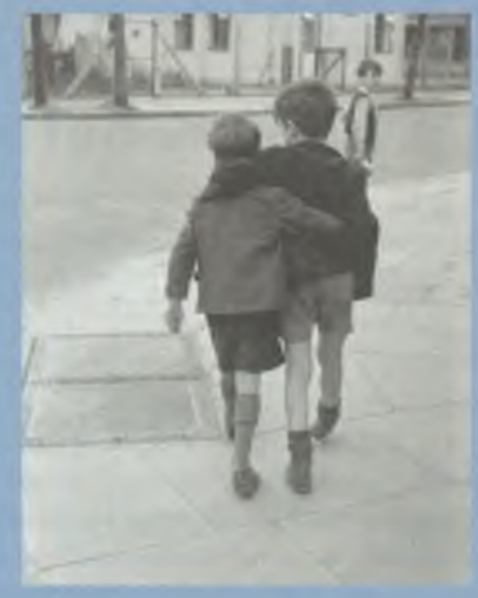

For years, Faxon has earned your trust through a commitment to personal service along with products, services, and systems that help your library access and manage your print and electronic collections.

\section{Subscription Depot}

Provides wob-based control of serials scquisition needs anytime. anywere Mandles alf serials transactions, inctuding ordecs. clitsh, paysent history. Delivers quick access to the current bobiographic and financial drta for more than 200.000 tities.

\section{License Depot ${ }^{\text {wn }}$}

Whos elimkate the frustrations of o-jouraal Hcensing and registates Provides immediate web-based access to electronic jumv/licersing and registration terms and conditions. Gives you intast access to data about 5,000 plus joumal tites.

\section{kStore}

hotenet-bseod service for managing knowledge resources from the and-ase's desktop.

\section{Information Quest}

Simplifes e-journat management from selection to access. Provides desktop access and delivery of full image content trom over 2,500 online journais.

\section{Serials Update Service (Sus)}

Convenient, searchable databaae provides daily up-to-the-minute access to bibliographic and/or order changes to serial titios.

for more information, cal yoer facon ssles representriva at 1.800-768-0039 ext 50s. 


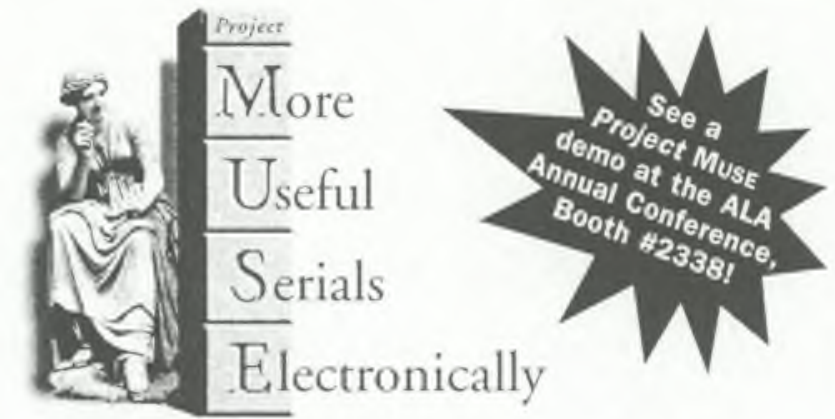

\section{Building a bigger, better Muse}

Project MUSE ${ }^{\infty}$ now includes scholarly journals from eleven university presses! Building on the original 47 scholarly titles offered by Johns Hopkins, the MUSE collection now offers 113 full-text journals online. By merging these titles into a single database, MUSE provides scholars with the critical content they need, combined with all of the benefits of electronic subscriptions, including full-text and field searching, easy navigation, and full campus availability 24 hours a day. With our expanded list, faster servers and increased searching options, your users will find research has never been easier. And as a librarian, there's no better value for your dollar-the list price of $\$ 8,000$ is much less than the cost of subscribing to these titles in print. Our flexible subscription options include discipline-oriented packages and single-title ordering to best meet your collection development needs. Substantial discounts are also offered for consortium, smaller and special libraries. Contact us now to see why there's more to MUSE than ever before.

\section{Now Muse includes journals from:}

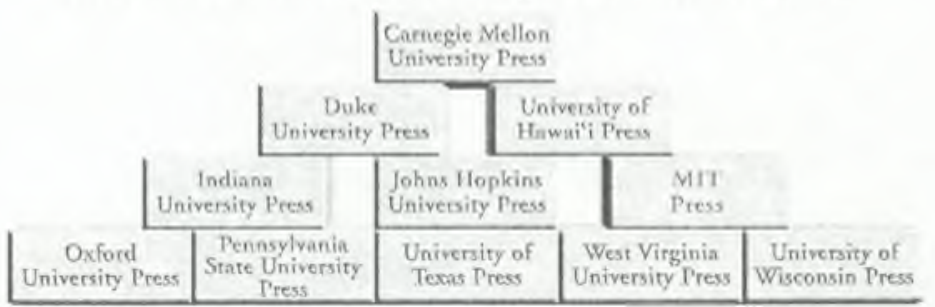

\section{Project Muse $^{(2)}$}

Setting the standard for scholarly electronic journals in the humanities and social sciences.

http://muse.jhu,edu

Preview the expanded Project MUSE now. Contact us for your free trial subscription at muse@muse.jhu.edu or 1-800-548-1784.
See what we've built. The Johns Hopkins University Press 